\title{
Publicidad y mercado. Estrategias del diseño en la sociedad de la comunicación
}

\author{
Francisco Silvestre Navarro 1 \\ Pablo Camarasa Balaguer² \\ Universidad Politécnica de Valencia. España
}

RECIBIDO: 5.01.2017 / ACEPTADO: 30.01.2017

\section{Resumen}

El presente texto indaga en las relaciones establecidas entre el mundo del diseño y el de la mercadotecnia buscando poner en valor la figura de varios profesionales de carácter creativo que estuvieron dispuestos a trabajar en gran disparidad de campos, como el del diseño gráfico, el de producto, la arquitectura, la escenografía o incluso el diseño aeronáutico, para acabar constituyendo la profesión de diseñador industrial. Una disciplina que en la actualidad sigue estando fuertemente vinculada al mercado y que tomó fuerza en los años en los que se ligó a la publicidad haciendo uso de los medios de comunicación para llegar a la ciudadanía, con diversas estrategias publicitarias llevadas a cabo en los primeros años del surgimiento del diseño industrial. Desde la celebración de ferias y la publicación de catálogos de venta, hasta la utilización de los propios productos y su embalaje como elemento anunciador, con la creación de las imágenes corporativas y los logotipos, las técnicas de la mercadotecnia fueron especializándose en favor del diseño, estableciendo lazos indisolubles entre el mercado y el diseño.

Palabras clave: publicidad, mercado, diseño, producto, comunicación.

\section{Publicity and marketing. Design strategies in the communication society}

\begin{abstract}
The present text delves in the relations established between the world of the design and the marketing seeking for to put in value the figure of some professionals of creative character who were willing to work in great disparity of fields, like the graphic design, product design, architecture, scenography or aeronautical design, to end up being the profession of industrial designer. A discipline that currently continues to be strongly linked to the market, and that took force in the years in which it was linked to advertising making use of the media to reach citizenship, with diverse advertising strategies carried

\footnotetext{
1 Francisco Silvestre Navarro (Valencia, 1976) es Doctor Arquitecto por la Universidad Politécnica de Valencia, donde ejerce como profesor. Tras dos años en el estudio de Álvaro Siza (2002-2004) regresó a Valencia para constituir su propio estudio, Fran Silvestre Arquitectos.

2 Pablo Camarasa Balaguer (Yecla, 1984) es Doctor en Historia del Arte por la Universidad de Valencia, Arquitecto por la Universidad
} Europea de Madrid y máster MArch por la misma institución. Actualmente forma parte del equipo de Fran Silvestre Arquitectos.
\end{abstract}


out in the early years of the rise of industrial design. From the celebration of fairs and the publication of sales catalogs, to the use of the products and ther packaging as an announcer, with the creation of corporate images and logos, marketing techniques were specializing in favor of design, establishing indisoluble links between the market and design.

Keywords: publicity, marketing, design, product, communication.

Remontándose al siglo XIX, las técnicas de comunicación empleadas por parte de la industria para dar a conocer determinados objetos y productos han sido muy variadas, tanto en escala, como en contenido. Pueden citarse, casi estableciendo una cronología, las ferias, los catálogos de venta directa, los anuncios en revistas, los libros, los anuncios en emisoras de radio y los ya más recientes anuncios en televisión. Pero no puede dejarse de lado la influencia que ejerció el propio diseño de los objetos desde el punto de vista de la publicidad.

Desde sus orígenes, las exposiciones y ferias han sido habituales para dar a conocer los nuevos avances. Ya en 1914 se celebró en Colonia una gran exposición organizada por la organización alemana Deutscher Werkbund, a la que sucederían otras notables muestras hasta llegar a la Gran Exposición Universal de Nueva York de $1939^{3}$. El propósito de estas ferias no era únicamente mostrar las novedades de la época, sino que también pretendían educar a la población promoviendo el "buen gusto" a través de las nuevas formas pensadas y bien fabricadas. Para ello, hicieron uso de medios como las publicaciones de catálogos de venta como el Deutsches Warebuch-Libro de Productos Alemanes-, que llegó a un elevado número de ciudadanos, aunque en el caso de la Deutscher Werkbund tenía la finalidad de lograr entre el pueblo alemán, a través del arte y el trabajo de calidad, el nacimiento de un sentimiento de superioridad de los productos alemanes con respecto al resto de competidores del mercado mundial.

Algunas personalidades contemporáneas, como el político Friedrich Naumann, creían que carecía de sentido que la industria alemana inundase el mercado mundial con una sobreproducción ya que esto solo estaba al alcance de los países que poseían más materias primas -como sucedería más tarde con Estados Unidos-, de manera que el diseño alemán apostaba por ocuparse de la fabricación de objetos con una producción limitada. Ejemplos de ello son el pintor y publicista Heinrich Mittag, a quien se le encargó que rediseñara el embalaje de las galletas Bahlsen, y el del diseñador Fritz Hellmut Ehmcke, quien se ocupó del diseño de los paquetes para los cigarrillos Feinhals. Los productos vieron incrementadas sus ventas a raíz de ser portadores, en sus nuevos embalajes, del sello de la DWB (acrónimo de la Deutscher Werkbund), lo que los convierte en una muestra del éxito de la promoción y las ideas del Werkbund.

En cualquier caso, los catálogos de venta consiguieron acercar los nuevos diseños al grueso de la población, y actuaron como elemento de promoción a la par que de educación, de modo que, mientras informaban a los usuarios de las últimas novedades, iban creando entre los mismos la idea de unos productos alemanes de excelente calidad.

En Estados Unidos, los catálogos de venta de productos fueron muy populares y contribuyeron notablemente a la expansión comercial de los objetos producidos. Los anuarios Sears, Roebuck and Co. o

${ }^{3}$ Como la organizada por la ÖWB, la asociación de la Werkbund en Austria, y celebrada en Viena en 1930. 
Bennett Brothers Inc., se describían a sí mismos como un espejo de su tiempo que serviría para recordar a los futuros historiadores los deseos, hábitos, costumbres y estilos de vida de aquel entonces. Gracias a ellos, las regiones rurales más alejadas de los grandes núcleos urbanos pudieron conocer la existencia de los últimos avances y contar con la posibilidad de adquirirlos para su propio uso.

Estos catálogos ya se distribuían a finales del siglo XIX y su utilización se prolongó durante mucho tiempo. El hecho de poder adquirir cualquier objeto diseñado en aquella época, desde un grifo a una bicicleta, bien en Nueva York o bien en cualquier pequeña ciudad del centro del país, suponía un gran avance y contribuía a recortar las diferencias existentes entre la vida urbana y la rural (ver fig. 1).

Pero también en las primeras décadas del siglo $X X$ empezaron a surgir nuevas políticas de ventas que abarcaban desde la forma del objeto hasta la manera de hacerlo llegar al público, y sobre todo fue determinante el papel de las compañías de suministro eléctrico, pues eran las más interesadas en que se crease y produjese una variada gama de productos dependientes de la electricidad que a la vez fuesen de rápida obsolescencia para mantener un mercado en constante movimiento. En Estados Unidos, numerosas empresas contrataron los servicios de los nuevos profesionales dedicados al diseño industrial, lo que dio lugar al styling, corriente estética que vino acompañada de un desarrollo de carácter mediático que derivó en una importante inversión en publicidad dirigida a cartelería, radio y televisión. Esta revolución publicitaria marcaría un antes y un después en la historia del comercio, pues a partir de entonces, las estrategias de mercadotecnia estarían muy ligadas al incremento de los ingresos de las empresas que hiciesen uso de las mismas (ver fig. 2).

Estas estrategias en Norteamérica condujeron a que los Estados Unidos se colocasen por delante de Europa, donde también en diversos países se produjo una concienciación de la necesidad de reactivar la sociedad de consumo a través de la producción de objetos de menor precio. Ejemplo de ello fue la arquitecta y diseñadora francesa Charlotte Perriand, quien, comprometida con la sociedad, acometió los diseños de diferentes objetos de mobiliario doméstico de precio asequible para los bolsillos de aquellos estratos sociales golpeados por la crisis. Medidas que, sin la intervención de campañas publicitarias como las llevadas a cabo por los estadounidenses, no hubiesen obtenido unos resultados tan beneficiosos.

También durante la Segunda Guerra Mundial siguieron produciéndose cambios en las estrategias comerciales de las grandes compañías, como fue el caso de Coca-Cola, que, con el que fuera su director general al frente desde 1923 hasta 1954, Robert W. Woodruff, consiguió persuadir al ejército de que su producto era esencial para los combatientes puesto que satisfacía los gustos de todos ellos. Tras la aceptación, aumentaron la producción y, aunque no obtuvieron beneficios de forma inmediata, con la aplicación de esta estrategia, consiguieron consolidarse en el mercado internacional y desde 1945 hasta 1955 alcanzaron el mayor crecimiento de la compañía ${ }^{4}$. En esos mismos años, contrataron al diseñador estadounidense de origen francés Raymond Loewy para que rediseñara el botellín clásico de vidrio, lo cual era una nueva muestra de la importante apuesta por la publicidad que llevaban tiempo haciendo, pues, aunque Loewy era conocido por sus diseños styling, también lo era por el papel mediático que había adquirido.

${ }^{4}$ BOSCH, Aurora. Historia de los Estados Unidos (1776-1945), Crítica, Barcelona 2005, pp. 457-458. 


\section{"We live in deeds, not years."}

Quite often, a youngster comes along to do what folks around him believe "can't be done." Quite often, too, such deeds prove again that it's what you do that counts. Not how long you've been around.

That's why today, as ever, we strive to make Sears catalogs serve more people better. This big, new book, for example, brings you much new merchandise, developed to fill your needs in new and better ways. And it offers you lower prices than last Fall on hundreds of items.

Only so long as we keep doing such things to make our books more useful to you, can we hope to deserve your business. That's the basis on which we ask you to order from this new catalog, or from any Sears book.

Satisfaction Guaranteed or Your Money Back

SEARS, ROEBUCK AND CO. 925 S. Homan Ave., Chicago 7, Ill. SPRING AND SUMMER 1954

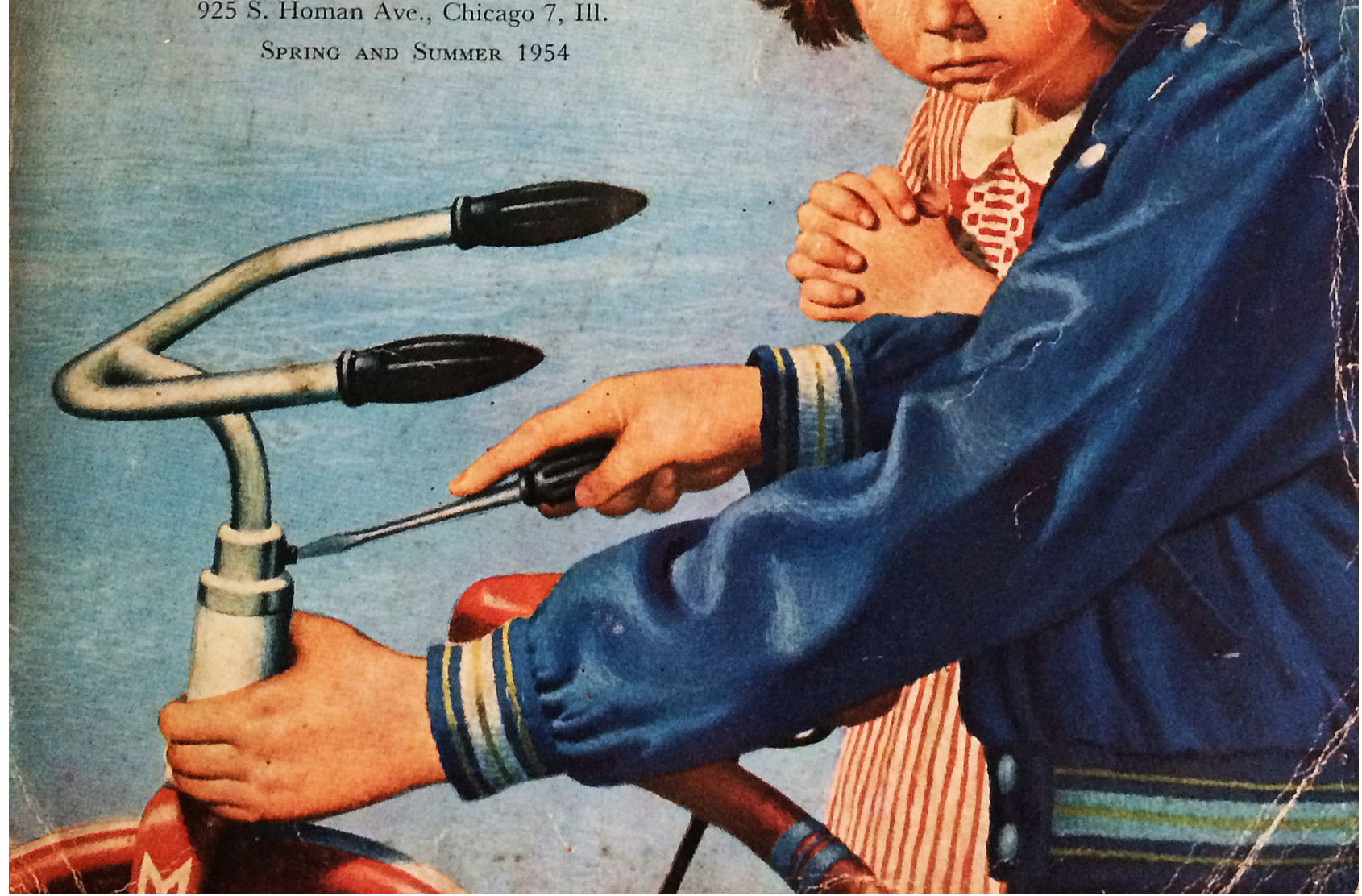

Fig.1. Contraportada del catálogo de venta Sears, Roebuck and Co. de 1954. 


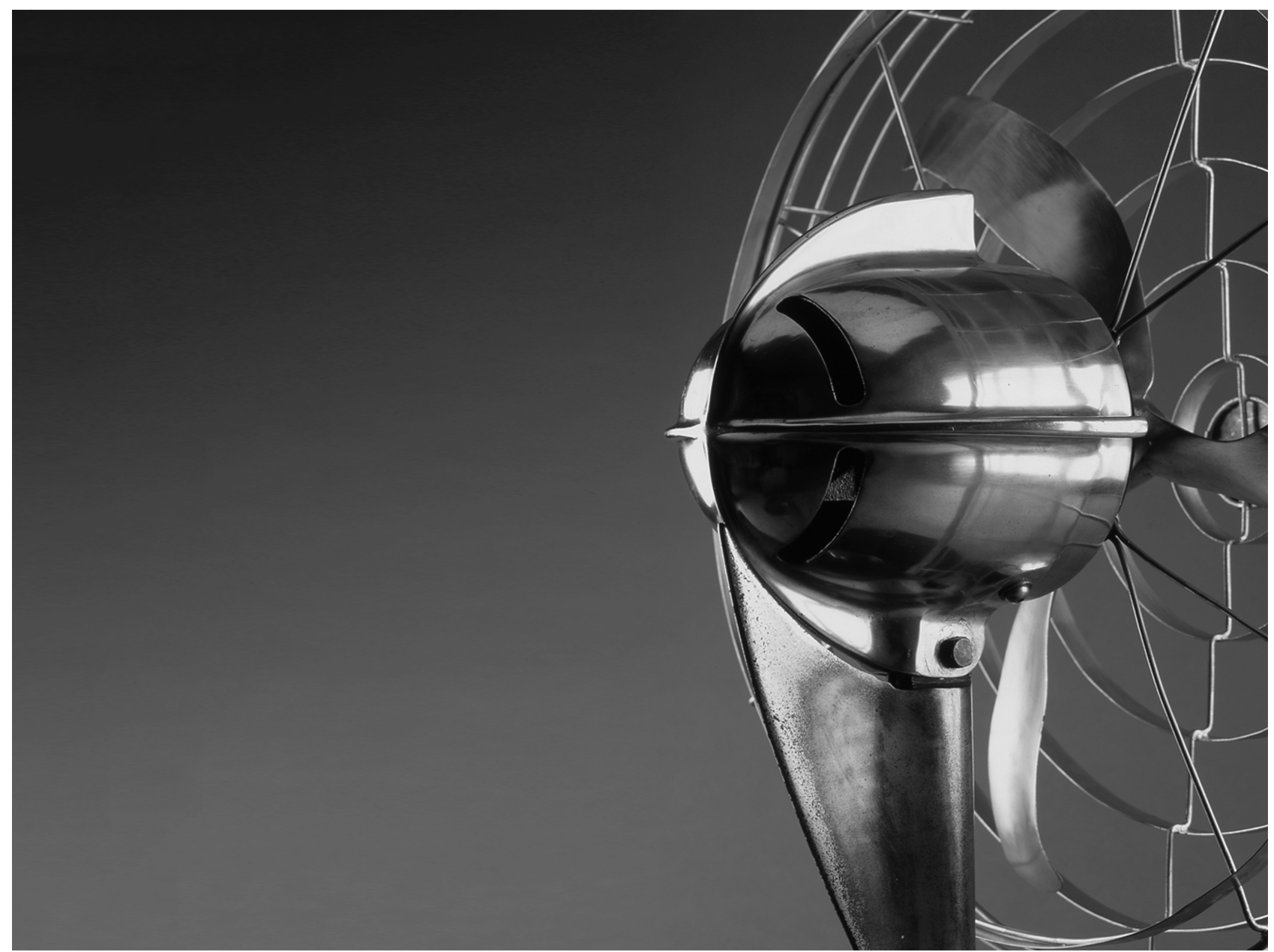

Fig. 2. Ventilador D22-TL diseñado por Robert Davit Budlong para Zephyr.

Fue el mismo Loewy quien en los años de 1940 se encargó del rediseño del paquete de tabaco de la marca Lucky Strike5, compañía a la que ayudó a incrementar sus ventas modificando el envoltorio, que originariamente era de color verde. La contratación por parte de su presidente, George Washington Hill, de este diseñador para que cambiara la imagen y el diseño de su producto, trajo consigo cuantiosos beneficios. Loewy diseñó un envoltorio en el que el fondo a partir de entonces iba a dejar de ser verde para pasar a ser blanco, de forma que el nombre era más legible, con el logotipo tanto en la parte delantera como en la trasera, y las descripciones en los laterales.

El cambio a blanco les permitiría ahorrar costes en cuanto a uso de color y, para justificarlo, trazó una campaña publicitaria en la que decía que el pigmento verde debía destinarse a la industria armamentística. Alegaba que "el verde se ha ido a la guerra", cosa que, desde el punto de vista publicitario, podía entenderse como un gesto patriótico, lo que revirtió de forma positiva en las ventas de la compañía. El resultado final habla por sí solo: tras la intervención de Loewy, las ventas aumentaron en un 17\%, y en los primeros diez años desde el rediseño se vendieron más de 50.000 millones de cajetillas ${ }^{6}$.

\footnotetext{
${ }^{5}$ BAYLEY, Stephen. The Lucky Strike packet by Raymond Loewy. Design Classics, Verlag Form, Basel 2002.

${ }^{6}$ CERVERA FANTONI, Ángel Luis. Envase y embalaje: la venta silenciosa, ESIC, Madrid 2003, p. 89.
} 
Junto con la Coca-Cola, los chicles Wrigley's Spearmint fueron otro ejemplo de readaptación. La compañía dirigida por Philip K. Wrigley se tuvo que enfrentar a una serie de sucesos que bien podrían haber acabado con la disolución de la empresa, pero ocurrió todo lo contrario. Se encontró con que desde 1941 el azúcar se racionó para el consumo, en torno a un $70-80 \%$, y la goma de mascar era mitad azúcar. Por otra parte, la savia con la que se hacía el chicle procedía de Malasia y de Borneo, entonces dominadas por Japón, o de Centroamérica y Sudamérica, donde había grandes dificultades para el transporte. Wrigley no se rindió y procuró mantener su acceso a las materias primas, abasteciéndose de los recursos americanos y descartando los asiáticos.

Desde el punto de vista comercial inició una campaña mediante la que pretendía demostrar que el chicle era beneficioso para los militares, puesto que al mascarlo, reducían la tensión, además de limpiar la boca y aplacar la sed. Invirtió dos millones de dólares en publicidad para la radio en la que destacaba el papel del ejército e indirectamente anunciaba los Wrigley's Spearmint ${ }^{7}$. Con ésto consiguió aumentar sus beneficios y posicionarse como una de las más importantes empresas del mercado. Asimismo, contó con el trabajo de diseñadores para que idearan campañas publicitarias, y resultado de ello fue aquella famosa en la que aparecía una bella mujer y bajo la misma un texto que decía The Girl with the Wrigley Eyes ${ }^{8}$.

Algunos de estos casos son la muestra de un trabajo que, desde su estamento ejecutivo sufrió una transformación que dio como resultado la creación de nuevos departamentos y la incorporación de aquellos recién surgidos profesionales que dotarían a los grupos contratantes de un carácter multidisciplinar. Las estrategias capitalistas trajeron algunos elementos menos deseables, como la obsolescencia programada, pero también aportaron otros interesantes, de clave social, como la orientación de mercado y la democratización de los bienes.

La comercialización del petróleo trajo consigo un nuevo modelo de ciudad. Asimismo la estandarización desde el punto de vista constructivo se enfatizó y se hizo más visible en cuanto a la importancia que empezó a concedérsele a los logotipos corporativos y el uso del color en los mismos. En determinados tipos como las estaciones de servicio, el aluminio y el vidrio se convirtieron en materiales comunes.

La gasolinera, para la venta al público de combustible, aumentó su oferta en torno a los años 30 y 40 , con programas que ofrecían una variedad de servicios para el automóvil. La evolución del término gasolinera a estación de servicio implicó además el cambio de un edificio que pasó a ser más complejo y que atrajo la atención de diseñadores industriales y arquitectos. A pesar de lo común de este modelo arquitectónico, durante el siglo XX surgieron progresivamente diferentes formas y estilos que tuvieron una gran influencia y repercusión en el diseño corporativo de las compañías distribuidoras de combustibles. Es el caso de Texaco, fundada en 1901 por Joseph S. Cullinan, Thomas Donoghue, Walter Benona Sharp y Arnold Schlaet y que décadas más tarde, ya consolidada en el mercado como una de las compañías más fuertes del sector, contaría con los diseños de Walter Dorwin Teague.

\footnotetext{
${ }^{7}$ BOSCH, Aurora. Historia de los Estados Unidos (1776-1945), Crítica, Barcelona 2005, p. 458.

${ }^{8}$ HAIG, Matt. Brand success: How the World's Top 100 brands thrive and survive, 2nd ed. Kogan-Page, London 2011, p. 42.
} 
En el diseño de estos tipos cobró probablemente mayor importancia la identidad corporativa de la marca a favor de la publicidad. De este modo, la compañía Texaco apostó por el diseño de una serie limitada de arquitecturas de formas estandarizadas que permitiera su rápida asociación con la venta de combustible y productos asociados, cualquiera que fuera el lugar donde se emplazaran estas construcciones. Durante los años veinte y treinta la compañía llevó a cabo diferentes diseños dependiendo de la arquitectura de la zona. Al norte del estado la compañía introdujo edificios derivados de las formas de la arquitectura doméstica tradicional, mientras que al sur y al oeste construyó estaciones de servicio estilo Colonial modern o Mission que pretendían aparentar estuco y adobe. Siguiendo la estela de Texaco, otras empresas buscaban, mediante la contratación de estos profesionales y el rediseño de sus estaciones de servicio, obtener los mismos resultados que su competidora?.

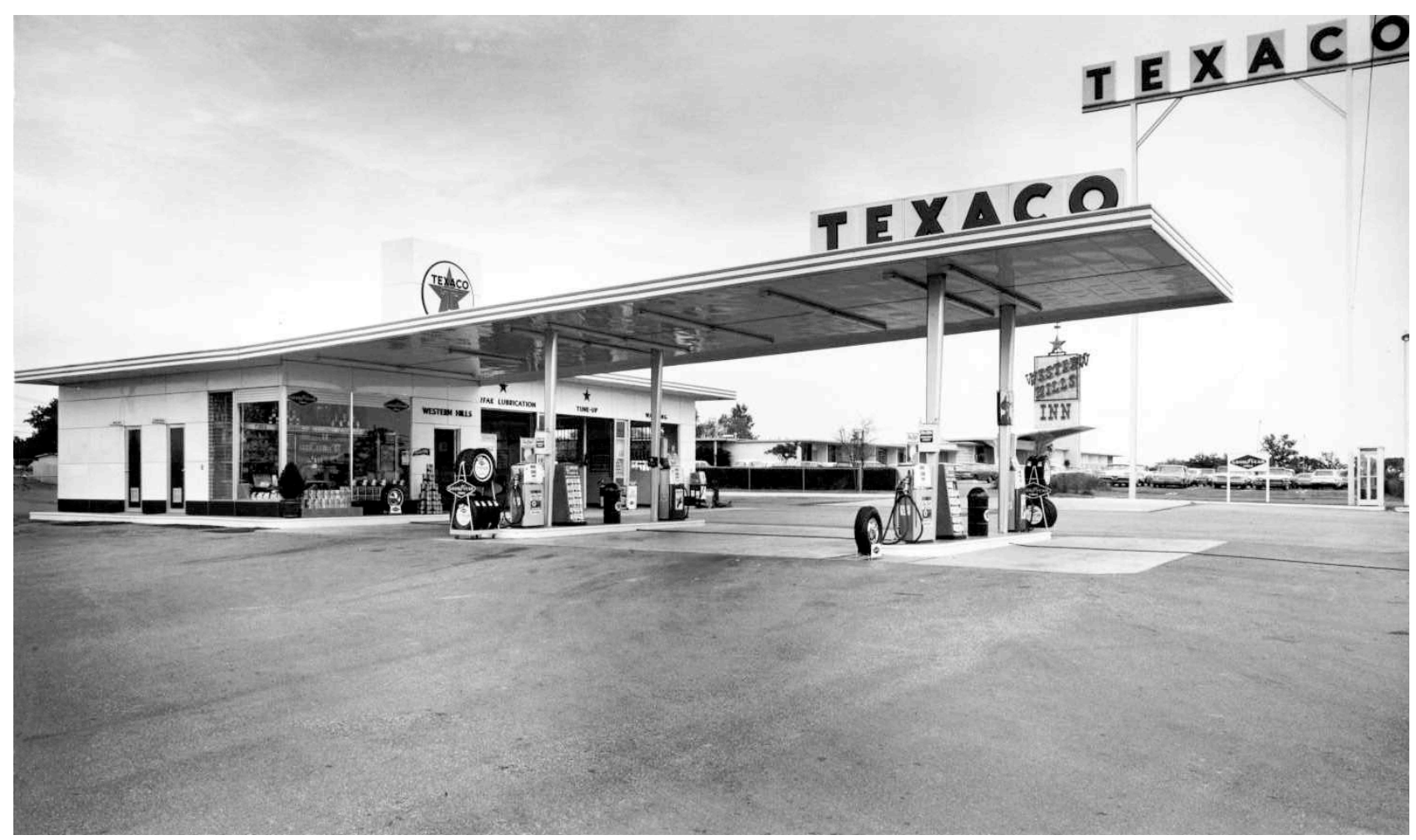

Fig. 3. Estación de servicio Texaco, diseño de Walter Dorwin Teague.

Muchas estaciones de servicio adoptaron revestimientos porcelánicos y comenzaron a otorgar mayor importancia a sus logotipos. Los propietarios de estaciones independientes proyectaron su individualidad mediante sus diseños, modificando o construyendo sus edificios para llamar la atención y poder así ganar una parte del mercado de este competitivo negocio. Fue un periodo en el que las compañías firmaban contratos de exclusividad con los diseñadores, llamados marketing engineers, que actuaban como "arquitectos diseñadores" asegurando la constancia y repetición de los edificios por todo un país. Durante estos años, uno de los más importantes arquitectos del siglo, Frank Lloyd Wright, diseñó una estación, su

9 JONES, W. Dwayne. A field guide to gas stations in Texas, Texas Department of Transportation, Austin 2003, p. 46. 
propia versión de una "moderna" estación de servicio construida en Minnesota10 que, sin embargo, no llegó a convertirse en un diseño estandarizado capaz de extenderse por todo el estado como sí ocurriese con los diseños de Teague para Texaco años antes, construcciones que perduraron a lo largo de tres décadas.

El principal motivo respecto a por qué el modelo de gasolinera de Lloyd Wright no se extendió como sí lo hizo el de Teague puede residir en la inversión en publicidad que cada una de las empresas de suministro de combustible hizo en cada caso. Este hecho es una muestra de la competencia que llegó a producirse en aquel entonces por abrirse un hueco en el mercado, y las dificultades de conseguir el éxito para aquellos que no estaban directamente vinculados a los campos del marketing y la publicidad.

Desde el punto de vista de los profesionales, el papel desarrollado durante las crisis producidas por el conflicto bélico de la Primera Guerra Mundial en Europa, y la Gran Depresión en Estados Unidos, por parte de aquellos grupos que sentaron las bases de una disciplina profesional tan prolífica como la del Diseño Industrial, dio lugar a un nuevo mercado y a una nueva forma de llegar a los individuos - la mercadotecnia-, fue crucial para la superación de unos periodos que parecían protagonizar la decadencia de un sistema. La gente empezó a formar parte de un mundo completamente distinto al de sus padres ${ }^{11}$, y muestra de ello era poder desplazarse en vehículos que se abastecían de combustible en gasolineras casi escultóricas, individuos que sabían lo que ocurría en el mundo a través de la radio, que compraban refrescos en máquinas expendedoras, o que cocinaban y realizaban las tareas del hogar con la ayuda de electrodomésticos ${ }^{12} \ldots$

Tras el crack de 1929 y el nacimiento de la profesión del diseñador industrial que dio lugar a un nuevo mercado, así como también a una nueva forma de llegar a la sociedad a través de la mercadotecnia, muchas empresas se vieron obligadas a sufrir reestructuraciones para incluir a estos nuevos profesionales. La readaptación de los procesos tayloristas y fordistas, a otras industrias, fue también importante para la regeneración económica del país. Para dar forma a esa innovadora corriente estética, se apeló a un cambio formal en relación directa con el nuevo mundo que estaba surgiendo, influido por el futurismo, que ensalzaba la velocidad y estaba basado en investigaciones técnico-científicas dirigidas a la creación de superficies y envolventes que ofreciesen menor resistencia de cara a los avances ingenieriles.

La actividad desarrollada por estos pioneros del diseño estadounidense se valió de disciplinas tales como el marketing y la comunicación, y a través de ellas transmitieron sus valores, difundieron su trabajo, su obra, y la pusieron en valor. Le Corbusier es el ejemplo extrapolable a la arquitectura. Para lograrlo, hizo uso de un mecanismo crucial como es la industria cultural y todos sus transmisores. Es decir, aprovechó las ventajas que el cine, la radio, las publicaciones periódicas y la publicidad trajeron consigo, implicándose hasta el

\footnotetext{
${ }^{10}$ RUSSELL, Tim. Fill'er up: The great american gas stations, Voyageur Press, St. Paul, MI 2007, p. 121.

${ }^{11}$ HOBSBAWM, Eric. Historia del siglo XX, 3a reimpresión, Crítica, Buenos Aires 1999, pp. 365-366.

12 INNES, Christopher. Designing modern America: Broadway to main Street, Yale University Press, Devon 2005, p. 8.
} 
punto de que, como Colomina plantea, la propia arquitectura pudo llegar a industrializarse ${ }^{13}$. El resultado es por todos conocido, y el papel mediático que desempeñó, en la sociedad de su tiempo, también.

Le Corbusier ya planteó la necesidad de readaptar la arquitectura al hombre de su tiempo buscando satisfacer las nuevas necesidades surgidas a raíz de los cuantiosos avances que se iban produciendo cada vez de forma más vertiginosa ${ }^{14}$. Loewy, Dreyfuss, Dorwin Teague y Bel Geddes llevaron este pensamiento a la práctica, dentro del campo del diseño industrial, haciendo uso de todos los medios a su alcance y consiguiendo, incluso, que fuese la sociedad quien se viera en la necesidad de tener que adaptarse a sus creaciones. Fueron éstos profesionales con una orientación de mercado muy acentuada $y$, atendiendo a las palabras pronunciadas por uno de los ellos, Henry Dreyfuss: "El diseño es un vendedor silencioso" 15 .

De esta forma, diseñadores como Raymond Loewy tomaron conciencia de la importancia de las herramientas que ofrecía la industria cultural para poder llegar al cliente, y pronto las pusieron en práctica, contribuyendo a que éste se convirtiera en una figura mediática derivada del marketing. Los resultados son los anteriormente expuestos, obteniendo récords de ventas para las compañías a las que prestó sus servicios (ver fig. 4).

En otros sectores profesionales como la industria del automóvil sucedió lo mismo: la necesidad de aumentar las ventas con respecto a sus competidores directos, para no perder cuota de mercado, supuso apostar fuerte por la comunicación. No sólo se rodearon de aquellos diseñadores, que en los años treinta en adelante aplicaron la estética styling sobre los diseños de muchos automóviles, sino que también, en algunos casos, apostaron por la contratación de nuevas figuras profesionales como las del publicista para que éstos se encargasen de la difusión de sus productos a través de las diferentes plataformas de comunicación. De ese modo comenzaron los anuncios de automóviles, a través de grandes carteles y de pinturas murales, a los que siguieron anuncios para televisión y revistas, requiriendo los servicios de directores de imagen, de fotografía, escenógrafos y otras nuevas disciplinas nacidas de la comunicación audiovisual.

Para los anuncios para las revistas, las empresas contrataron principalmente a fotógrafos, los cuales también vieron la oportunidad de especializarse para abordar toda una serie de encargos que necesitaban de profesionales preparados para poder lograr un buen resultado a través de su trabajo. En la actualidad esas estrategias se han venido manteniendo, y la mayoría de empresas del sector del automóvil invierten importantes sumas de dinero en difusión.

\footnotetext{
${ }^{13}$ COLOMINA, Beatriz. Privacidad y publicidad. La arquitectura moderna como medio de comunicación de masas, CENDEAC, Murcia 2010, p. 90. Como la propia autora de este libro comenta, Le Corbusier entró en contacto con la cultura de los medios de comunicación de masas a través de su vinculación con la revista L'Esprit Nouveau, donde él mismo se encargaba de conseguir anunciantes, los cuales, en la mayoría de los casos y por decisión del propio Le Corbusier, eran industriales o empresarios que podían ayudarle a llegar hasta sus objetivos

${ }^{14}$ LE CORBUSIER. Hacia una arquitectura, Apóstrofe, Barcelona 2006.

${ }^{15}$ GANTZ, Carroll. Founders of American Industrial Design, McFarland and Company Inc. Jefferson, NC 2014.
} 


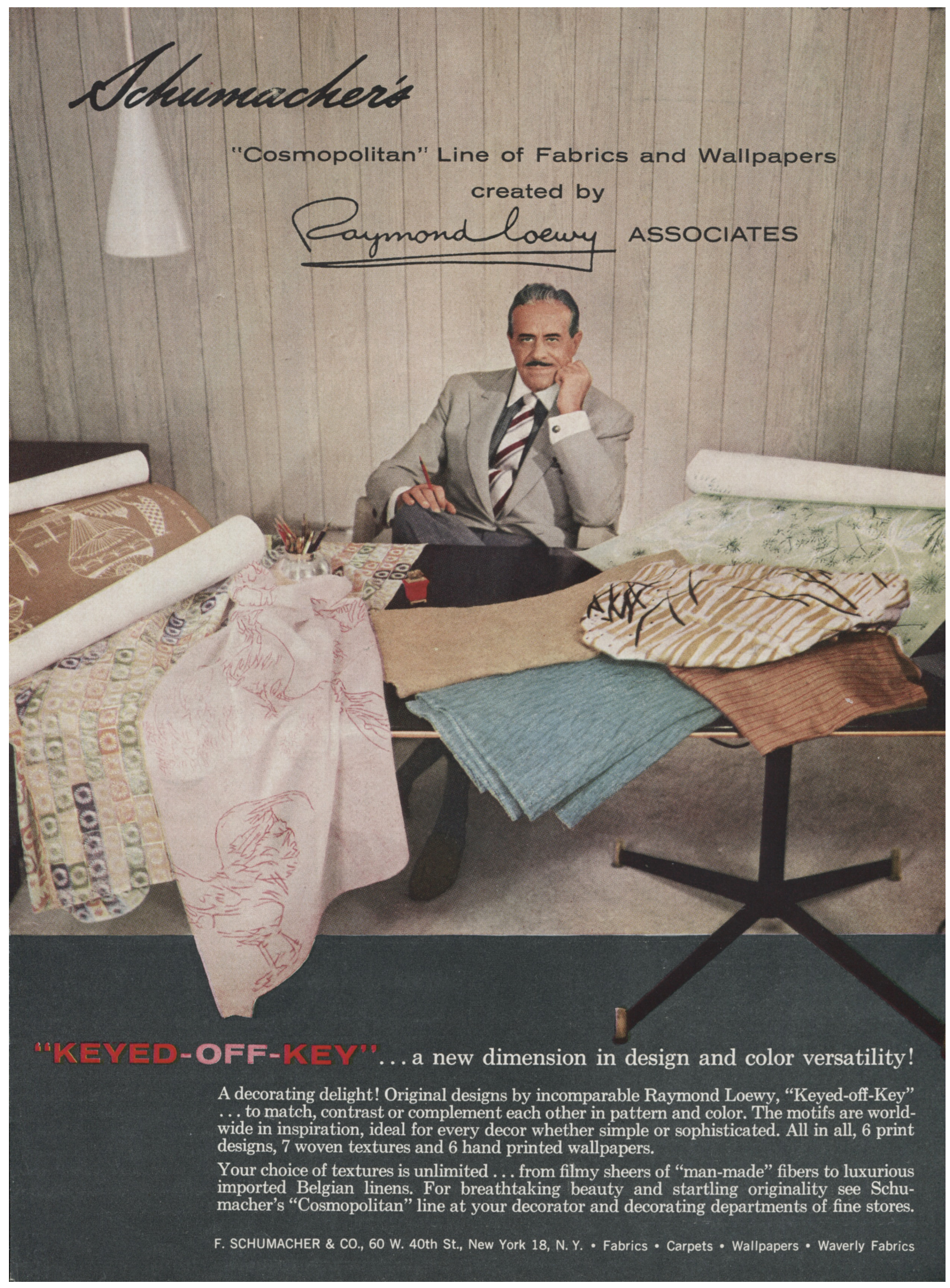

Fig. 4. Anuncio de la empresa Schumacher's con Raymond Loewy. 
Otro aspecto que muestra la destreza y la capacidad innovadora del sector fue la transformación de las marcas de los productos en iconos de las compañías a las que pertenecían. La importancia de hacer uso de los emblemas de marca, a modo de escudos heráldicos de la compañía, permitía y permite que la empresa o el estudio, en caso de ser rentable, pudiera sobrevivir más allá de su fundador, convirtiendo la marca en la garantía del producto. El significado de identidad corporativa es sinónimo de valores y formas de hacer de un grupo empresarial. Los pioneros aquí citados establecieron en sus orígenes pequeñas empresas que crecieron de forma exponencial.

Un buen ejemplo al respecto son la compañía formada por Walter Dorwin Teague, que en la actualidad sigue trabajando bajo el nombre de Teague, y que recientemente fue premiada con un Red Dot Design Award, manteniendo sus valores primigenios, o la fundada por el arquitecto valenciano Rafael Guastavino en Estados Unidos, Guastavino Fireproof Construction Company, que siguió en funcionamiento tras su muerte dirigida por su hijo, quien continuó al frente del negocio hasta 1943, año en que vendió su parte a su socio Malcolm S. Blodgett. Éste último se encargaría de mantenerla en funcionamiento hasta el año 1962, aunque lo más significativo es que no sólo constituyó una marca sólida e identificable para las gentes de la época, sino que también patentó un sistema constructivo, bautizado como Guastavino System, consistente en el proceso de construcción de la bóveda de ladrillo plano que alcanzaría gran popularidad en la época.

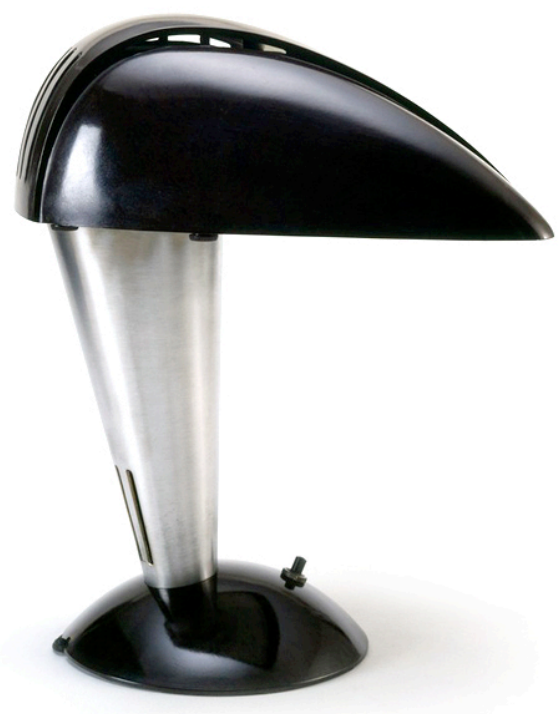

Fig. 5. Desk Lamp diseño de Walter Dorwin Teague.

También se pueden extraer enseñanzas del papel desempeñado por grandes corporaciones que, no ajenas a la importancia del diseño, optaron por potenciar la marca por encima de la figura de sus respectivos diseñadores. Son relevantes los casos de las empresas Braun - con Dieter Rams a la cabeza - o Apple con Jonathan Ive al frente del equipo de diseño-, quienes crearon formas que bien podrían ser 
consideradas artísticas. Se trata de empresas que en la fusión de artesanía e industria, siendo fieles a sus valores, y en el desarrollo del branding, consideraron desde un primer momento que el fabricante es lo más importante (ver fig. 6).

Fabricantes y diseñadores se fueron encargando de incluir nuevas variables en el campo del diseño industrial, desde materiales, tipos, durabilidad, reciclaje... Así como también en la promoción y venta del mismo, incorporando nuevos procesos de mercadotecnia y publicidad, desconocidos hasta entonces por el sector. El desarrollo de la mercadotecnia permitió tender puentes entre el fabricante y el usuario final, dando lugar a la existencia de una especie de empatía entre ambos que contribuía a hacer del producto un bien más próximo a las exigencias de éste. Se dio una orientación de mercado que tendía hacia la especialización, llevando a la mejora continua de los objetos. Fueron éstos factores positivos de la mercadotecnia.

En este periodo de la historia, la cultura visual será de suma importancia. Ésta ya no se basa en imágenes fugaces, sino en capturas que encierran toda una serie de criterios. La imagen contribuirá a potenciar el objeto en cuestión o incluso la arquitectura fotografiada. El escritor y crítico de arquitectura Reyner Banham definió el Movimiento Moderno como el primer movimiento, en la historia del arte y la arquitectura, que se quedaba sujeto de forma exclusiva a la "evidencia fotográfica", posicionándola por encima de la propia experiencia personal, los libros convencionales o los mismos dibujos ${ }^{16}$, de manera que, desde entonces, la fotografía se ha convertido en el principal aliado de la arquitectura, llevando a que el edificio deba ser entendido en los mismos términos que en una imagen.

Generar material, ya sea éste visual o textual, y propagarlo a través de las diferentes herramientas comunicativas existentes en la actualidad, contribuye a la transformación pública de las disciplinas creativas, de manera que consigue llegar a más gente, dando lugar a la posibilidad de aumentar el número de clientes para el profesional. Empleando como ejemplo la arquitectura del Movimiento Moderno, en torno a ella se formó una visión convencional, entendida como disciplina artística creada por oposición a la arquitectura de masas y a la vida cotidiana ${ }^{17}$. Bajo estos prejuicios se obviaba la unión existente (e, incluso, necesaria en la mayoría de los casos) entre el mundo del diseño y la cultura de masas ${ }^{18}$, contribuyendo a un alejamiento entre el trabajo del diseñador y el interés o el conocimiento acerca del mismo que pudiese suscitar en la sociedad.

Hasta el siglo XX, en Estados Unidos los arquitectos eran criticados si hacían uso de la publicidad para darse a conocer o para promocionar sus trabajos, e incluso el AIA (Instituto Americano de Arquitectos) se

\footnotetext{
${ }^{16}$ COLOMINA, Beatriz, op. cit. p. 28

17 Ibidem.

${ }^{18}$ Como ya se ha visto anteriormente, Le Corbusier fue uno de los primeros arquitectos en poner en valor la importancia de los medios de comunicación, pero, como señala Dennis P. Doordan, tal vez se vio inspirado por Fortunato Depero, quien antes que él ya había comenzado a dar importancia a la publicidad, como demostró en el diseño del pabellón de Venezia Tridentina, para la feria de Milán en 1924, diseño que no llegó a construirse por considerarse demasiado costoso, pero que, el propio Depero, una vez generado el material necesario para su construcción, se encargó de difundirlo. En DOORDAN, Dennis P. "The Advertising Architecture of Fortunato Depero", The Journal of Decorative and Propaganda Arts, vol. 12. Florida International University Board of Trustees on behalf of The WolfsonianFIU, 1989, pp. 46-55
} 
oponía a que hiciesen uso de esta herramienta publicitaria por considerarla como propia del comercio de baja calidad. Pero desde 1916 en adelante, algunos jóvenes arquitectos se alzaron contra la AIA, como fue el caso de David Knickerbacker Boyd, un joven profesional de Filadelfia que se enfrentó a dicho organismo exigiendo el uso de la comunicación en la arquitectura ${ }^{19}$. Años después, la decisión de ignorar la cultura de consumo sería considerada un escollo en la progresión de la figura del arquitecto. La Gran Depresión y la Segunda Guerra Mundial contribuyeron a que la AIA modificase su política, permitiendo al sector establecer relaciones con el campo de la publicidad e igualarse de este modo a otros sectores creativos como por ejemplo el del diseño de producto.

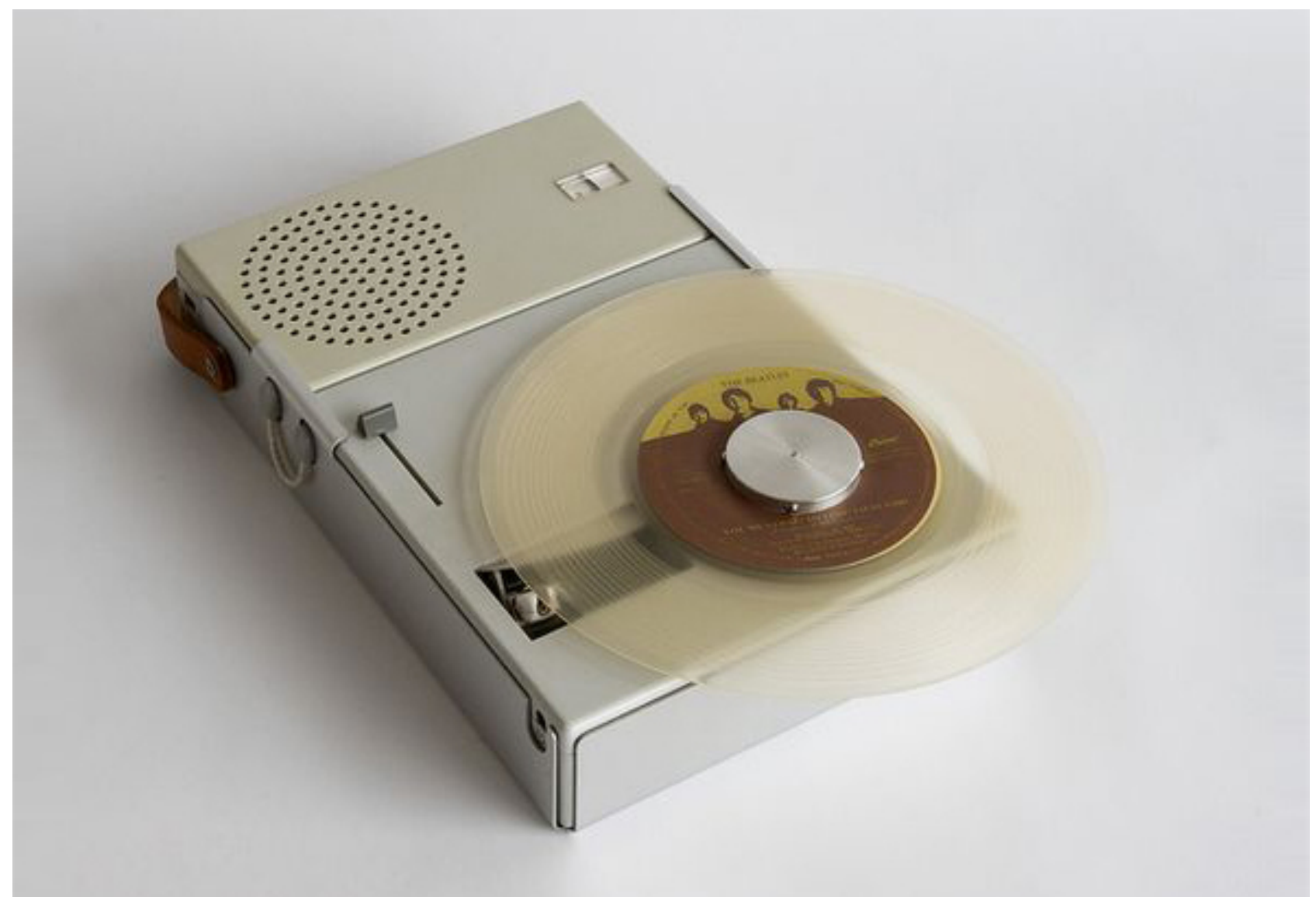

Fig. 6. eTocadiscos TP1 para Braun diseñado por Dieter Rams, 1959. Foto: Reme Samper.

\footnotetext{
19 SHANKEN, Andrew M. "Breaking the Taboo: Architects and Advertising in Depression and War". Journal of the Society of Architectural Historians, vol. 69, num. 3, 09/10. University of California Press, 2010, pp. 406-407. En este artículo, el autor recoge una cita de un arquitecto que criticó la política de la AIA, considerándola un obstáculo para su carrera: "Every architect probably sleeps on an advertised mattress, bathes every morning an advertised soap, uses and advertised tooth paste on an advertised tooth brush, puts on an advertised suit of clothes, eats an advertised breakfast food and starts to his day's work, after putting on an advertised hat and coat. Thereupon he sets out on his daily tasks. He must strenuously avoid everything that savors of advertising the measure of his own ability or else risk the wrath of the governing body of his profession. Is this consistent?" (“Cada arquitecto, probablemente, duerme en un colchón anunciado, se baña cada mañana usando un jabón publicitado, utiliza pasta de dientes anunciada en un cepillo de dientes anunciado, se viste con un traje publicitado, desayuna comida anunciada y comienza su día de trabajo después de haberse puesto su abrigo y sombrero anunciados. Entonces, él se embarca en sus tareas diarias. Debe evitar enérgicamente todo lo que tenga sabor a publicidad en la medida en que su propia capacidad le permita, o de lo contrario, arriesgarse a la ira del órgano de gobierno de su profesión. ¿Es esto coherente?”). [Traducción de los autores]
} 


\section{REFERENCIAS}

BAYLEY, Stephen. The Lucky Strike packet by Raymond Loewy. Design Classics, Verlag Form, Basel 2002.

BOSCH, Aurora. Historia de los Estados Unidos (1776-1945), Crítica, Barcelona 2005.

CERVERA FANTONI, Ángel Luis. Envase y embalaje: la venta silenciosa, ESIC, Madrid 2003.

COLOMINA, Beatriz. Privacidad y publicidad. La arquitectura moderna como medio de comunicación de masas,

CENDEAC, Murcia 2010.

DOORDAN, Dennis P. "The Advertising Architecture of Fortunato Depero". The Journal of Decorative and Propaganda Arts, vol. 12. Florida International University Board of Trustees on behalf of The Wolfsonian-FIU, 1989.

GANTZ, Carroll. Founders of American Industrial Design, McFarland and Company Inc. Jefferson, NC. 2014.

HAIG, Matt. Brand success: How the World's Top 100 brands thrive and survive. 2nd ed. Kogan-Page, London 2011.

HOBSBAWM, Eric. Historia del siglo XX, $3^{\text {a }}$ reimpresión, Crítica, Buenos Aires 1999, pp. 365-366.

INNES, Christopher. Designing modern America: Broadway to main Street. Yale University Press, Devon 2005, p. 8.

JONES, W. Dwayne. A field guide to gas stations in Texas, Texas Department of Transportation, Austin 2003.

LE CORBUSIER. Hacia una arquitectura, Apóstrofe, Barcelona 2006.

RUSSELL, Tim. Fill'er up: The great american gas stations, Voyageur Press, St. Paul, MI. 2007.

SHANKEN, Andrew M. "Breaking the Taboo: Architects and Advertising in Depression and War", Journal of the Society of Architectural Historians, vol. 69, num. 3, 09/10. University of California Press, 2010.

WALLERSTEIN, Immanuel. "El moderno sistema mundial", tomo III. La segunda era de gran expansión de la economíamundo capitalista 1730-1850, Siglo XXI, Madrid 1999. 